\title{
The Epidemic Of Scabies In Yaounde
}

\author{
J Mbuagbaw, C Bisseck, G Ozoh, M Etienne
}

\section{Citation}

J Mbuagbaw, C Bisseck, G Ozoh, M Etienne. The Epidemic Of Scabies In Yaounde. The Internet Journal of Dermatology. 2005 Volume 4 Number 2.

DOI: $\underline{10.5580 / \mathrm{aa} 2}$

\begin{abstract}
Sarcoptes scabiei the 'itch mite' is a human ectoparasite of worldwide distribution, which affects all ages and respects no social class. In developed countries the incidence of scabies has shown cyclical epidemics. A prospective study was carried out in two dermatology clinics in Yaoundé between 1991 and 2004. Out of 32,447 patients seen in the dermatology clinics during the study period, 2,738 (8.4\%) had scabies. The age range of the patients with scabies was 1 to 65 years.
\end{abstract}

There was an upsurge of the number of cases of scabies between 1991 and 2004. Majority of the patients came from lowincome quarters, where over crowding is common, and the tendency to have more than two children in one family bed.

We recommend that the management of cases of scabies should include the household and sex partners of the patients.

\section{INTRODUCTION}

Sarcoptis scarbiei variant hominis is of the genus astigmata. This mite is responsible for one of the most itchy skin conditions known.

Though worldwide, the tropical condition favors its spread. Other predisposing factors are overcrowding, poor personal hygiene, debilitating illness and immuno-depression. Man made condition like wars and natural disasters like famine, all of which lead to over crowding, poor hygiene, ill health and displacement of people also contribute. The infestation is present all year round but worse during the hottest and humid periods of the year (January to October). Infestations in man can reach epidemic proportions. $\left({ }_{1},{ }_{2}\right)$

The diagnosis can be easily made by the itchy nature of the condition, the affection of many members of a household, the distribution of the lesions, the burrows and identification of the mites.

The mite lives in the corneal layer of the skin and moves from one spot to the other by burrowing. It deposits eggs and excrements as it moves along; these materials are responsible for the pruritus, which is the main presenting complaint.

The epidemics of scabies follow a thirty-year cycle, 10 to 15 years of high incidence and 10 to 15 years of low incidence, and may last for $2-3$ years before diminishing $\left({ }_{3},{ }_{4}\right)$ but this cycle may change if there is an increase in the predisposing factors. The cycle may also be shorter because of adequate management and early development of herd immunity.

The mite is transmitted from skin to skin by close contact and does not survive longer than 48hours away from the skin. Skin to skin transmission is more important than from fomites $\left(_{5}\right)$. It may be transmitted sexually $\left(_{6}\right)$; hence scabies in a sexually active adult may warrant screening for other Sexually Transmitted Infections (STI's).

We were prompted to carry out a prospective study of scabies in our Dermatology clinics when we noticed the upsurge of the number of cases. As far as the nineteen eighties, scabies infestation was diagnosed occasionally in the out patient clinics. With time we observed a rising trend in the number of cases of scabies diagnosed during outpatient consultations in dermatology clinics. By the early nineties the number of cases continued to increase.

\section{OBJECTIVES}

Our objectives were to determine the epidemiological trends of scabies over a 17-year period in Yaoundé, Cameroon, from January 1998 to December 2004. 


\section{SUBJECTS AND METHODS}

A prospective study was carried out in two Dermatology Clinics in Yaoundé, the Military Hospital and the University Teaching Hospital (CHU), from January 1991 to December 2004. The diagnosis of scabies was made on the basis of:

1. Having a very itchy rash, worse at night.

2. Having many or all members of the household infested,

3. Characteristic distribution of papular vesicular excoriated rashes with occasional small nodules and with or without secondary bacterial infection, as may be the case with children.

4. Characteristic distribution of the rashes on the flexor aspects of the wrists, the finger webs, elbows, knees, areola and nipples in females, anterior axillary fold, buttocks and external genitalia in males. The lesions are usually generalized in children, extending from head to toe.

5. Characteristic burrows.

6. In doubtful cases, the burrows or other lesions were scraped and obtained material mounted on a slide. A drop of $10 \%$ potassium hydroxide was used to dissolve the keratin and the mite or its egg viewed under the microscope.

All patients who satisfied the above criteria were recruited. Patients who were HIV positive were excluded from the study as they presented an extra predisposing factor. Members of the family were invited for examination and recruited if they certified the above criteria.

\section{RESULTS}

Out of 38851 dermatology consultations, 2845 (7.3\%) had scabies. The age range was 1 to 65 years with $50 \%$ under age of 10 years. Male /female ratio was 2:3. The majority of the patients came from very low income quarters of the town. The characteristics were persistence of infections after "treatment". Inquiry revealed treatment of only infected members of the household and incorrectly or inadequately used scabicides. There were many cases of auto medication. The average number of patients seen per year with scabies during the peak incidence was 367 .
Table 1 shows the number of consultations per year and the number of cases of scabies in the two Dermatology clinics, the total numbers of Dermatology cases, the percentages and the $\mathrm{P}$ values. The number of cases was highest during the years 1995 to 2000 then tailed off gradually. From our findings the epidemic of high incidence could be said to have started in 1991, peaked during 1995 to 2000 and tailed off towards 2001 to 2004. By early 2001 the number of cases of scabies seen dropped markedly to an average of 60 cases per year. Figures 1 and 2 also illustrate this variation.

\section{Figure 1}

Table 1: Number of scabetic cases/total dermatology consultations per annum

\begin{tabular}{|l|l|l|l|l|}
\hline Year & $\begin{array}{l}\text { Number of } \\
\text { Cases of } \\
\text { Scabies }\end{array}$ & $\begin{array}{l}\text { Number of } \\
\text { Dermatology } \\
\text { Cases }\end{array}$ & $\begin{array}{l}\text { Percentages } \\
\text { of cases of } \\
\text { scabiesl } \\
\text { dermatology } \\
\text { consultations }\end{array}$ & P values \\
\hline 1988 & 50 & 1300 & 3.8 & \\
\hline 1989 & 60 & 1408 & 4.3 & 0.58 \\
\hline 1990 & 50 & 1500 & 3.3 & 0.47 \\
\hline 1991 & 70 & 1900 & 3.7 & 0.82 \\
\hline 1992 & 100 & 1800 & 5.5 & 0.03 \\
\hline 1993 & 90 & 1950 & 4.6 & 0.29 \\
\hline 1994 & 85 & 2185 & 3.8 & 0.95 \\
\hline 1995 & 236 & 2466 & 9.5 & $<0.001$ \\
\hline 1996 & 384 & 2532 & 15.2 & $<0.001$ \\
\hline 1997 & 426 & 2513 & 16.9 & $<0.001$ \\
\hline 1998 & 570 & 3009 & 18.9 & $<0.001$ \\
\hline 1999 & 416 & 3000 & 13.8 & $<0.001$ \\
\hline 2000 & 170 & 2822 & 5.8 & 0.004 \\
\hline 2001 & 96 & 2815 & 3.4 & 0.48 \\
\hline 2002 & 27 & 1401 & 1.9 & 0.002 \\
\hline 2003 & 54 & 1953 & 2.8 & 0.09 \\
\hline 2004 & 41 & 2097 & 1.9 & $<0.001$ \\
\hline Total & 2845 & 38851 & 7.3 & \\
\hline & & & & \\
\hline
\end{tabular}

The data obtained was analyzed using STATA version 8 . The $\mathrm{P}$ values were calculated using the Chi-squared test and compared each year to the base line taken as from 1988.

\section{Figure 2}

Figure 1

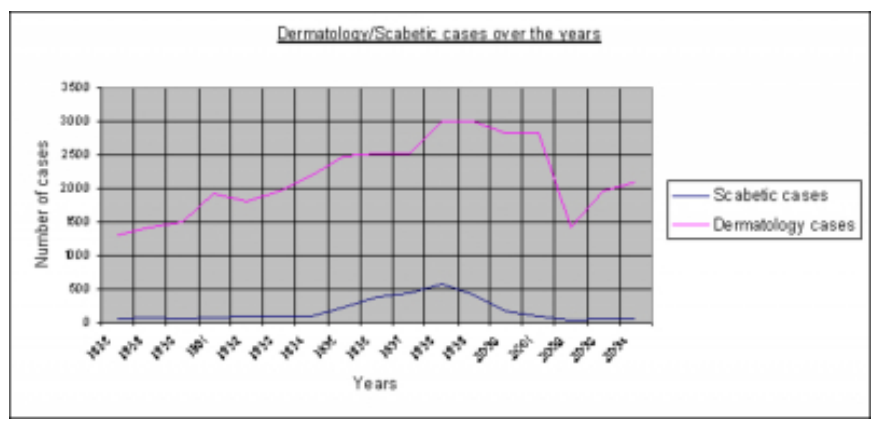




\section{Figure 3}

Figure 2

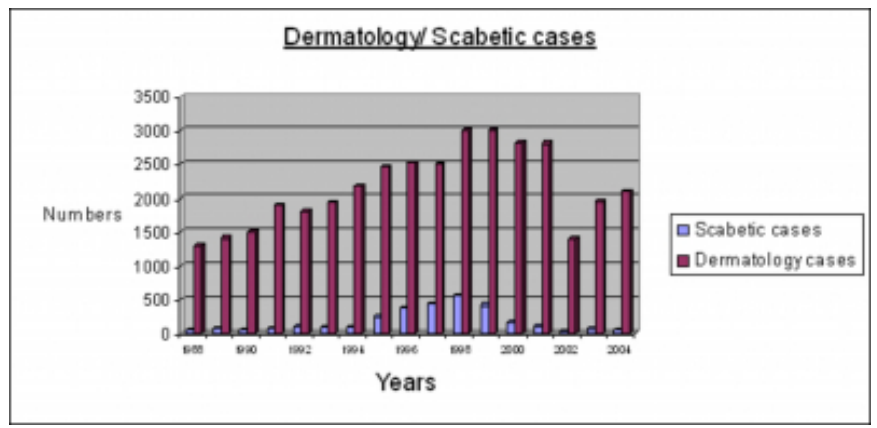

\section{DISCUSSION}

Many people consider scabies to be an affection for the low socioeconomic class. Unfortunately scabies is present worldwide and respects no social class. It is highly contagious and is responsible for a very itchy condition. The mite was first identified in 1687. Scabies was the first human disease with a known etiology $(7,8)$

The results of the present study (table 1) show that the prevalence of scabies in Yaoundé varies from year to year. In general, accurate incidence of scabies may be difficult to record for the following reasons; scabies is not a notifiable disease, diagnosis may be missed if there are associated itchy conditions, auto medication by the patient, and very mild infestations may be cleared by thorough scrubbing. Incidence fluctuates in developed countries. High incidence may correspond to periods of economic crisis, which may lead to sexual promiscuity, overcrowding, decrease in income and in the frequency of washing clothes and of scrubbing the body .As shown in table 1, the high prevalence of scabies recorded in Yaoundé Cameroon, coincided to the peak period of economic crisis in the country. Epidemics confer immunity and this leads to low prevalence. The epidemic may follow the theory of herd immunity ${ }_{9}$ ). The incidence remains low until a new susceptible population is present. This may explain the decreasing trend in the prevalence of scabies from 2001 to 2004.

The differential diagnoses of scabies are numerous, and may include all pruritic dermatoses, e.g. atopic dermatitis, drug reactions, dermatitis herpetiformis, urticaria and insect bites. The unusual presentation of scabies has been reported by many authors. $\left(_{10}\right)$ These include urticaria $\left(_{2}\right)$, dermatitis herpertifomis, $\left(_{4}\right)$ and bullous pemphigoid $\left(_{5}\right)$ to mention a few.

We had a 35 year old man who presented with nephritic syndrome, with proteinuria of $3 \mathrm{gram} / 24$ hours and a pruritic rash. Scabies was confirmed on microscopy. The patients' symptoms resolved after a course of systemic antibacterial treatment for secondary skin infection and treatment of the scabies.

Management poses both social and medical problems in our environment for the following reasons; the diagnosis may be missed while the patient continues to infect others, and the popular use of topical steroid creams as a skin lightening agent, and limiting treatment only to affected members of the family instead of treating both symptomatic and asymptomatic members of the household. The consequence of poor management is the persistence of infestation and reinfection of treated members of the family. This was the main characteristic of the epidemic in Yaoundé and it merited the local name of 'come no go'. Majority of the patients $(95 \%)$ came from high density quarters of Yaoundé were over crowding is rife. Many share beds. Some households have to go quite a distance to fetch water. This limited the frequency of baths.

Household contacts should be treated simultaneously with patients. Clothing worn within two days of treatment along with towel and bed sheets should be washed in hot water or dry cleaned. Clothing that cannot be washed should be sunned or ironed. Scabicides may be sprayed on the clothes and beddings.

Our routine treatment of scabies, included the use of Eurax cream which contains $10 \%$ crotamiton and 20\% Benzyl benzoate. We found Eurax cream very useful in children since it can be applied on the head and face; secondly it has good antipruritic effect, even though it is more expensive than Benzyl benzoate. We had no treatment complications. Cost was the limiting factor for the use of other scabicides.

There are advocates for systemic scabicides. Ivermectin (Mectizan) is a very potent scabicide especially in crusted scabies, after a single oral dose $\left({ }_{11},{ }_{12},{ }_{13},{ }_{14}\right)$. It is not readily available and we must consider coexistent parasitic infection, which may complicate its use especially in Loa loa infection. This microfilaria is common in our environment. We had no case of crusted scabies, which would have required the use of Ivermectin.

We conclude that a periodic high prevalence of scabies had occurred in Cameroon and this could have been due to the economic crisis and poor management of existing cases within households where other members of the household were not treated at the same time with the patients. We 
recommend that education of the population on proper use of scabicides will help to prevent chronic infection.

Health care providers should be fully aware that adequate control and treatment of scabies is very important.

Simultaneous treatment of patients and contacts whether symptomatic or not is a major means of control. This may help in preventing epidemics

\section{References}

1. Orkin M, Maibach HI. This scabies pandemic. New Engl J Med. 1978; 298:496-8.

2. Shrank A. B., Alexander S.L. Scabies: Another epidemic? British Medical Journal 1967; 1: 669-71.

3. Rook/Wilkinson/ Eblin. Textbook of dermatology, 5th edition, Vol 2, Chap. 29, Page 1300 - 1. Human Scabies, Incidence and epidemiology.

4. Meinking T, Taplin D. Infestations. In: Scachner L, Hansen R, editors. Paediatric Dermatology. New York: Churchill livingstone, 1995: 1347- 92.

5 . Mellanby K. The transmission of scabies. British Medical Journal 1941; 2: 405-6.

6. Melton LJ, Brazin SA, Damn SR. Scabies in the United
States Army. Am J Public Health 1978; 68: 77-8.

7. Stephen M., Scheicher, MD and Patricia Stewart, DO Scabies: The Mite that Roas. Emergency Medicine June 1997: Pages 54-58.

8. Thyresson N. (The remarkable debate during the beginning of the nineteenth century concerning the aetiology of scabies) Sydsvers Mandicinhist Sallsk Arsskr 1994; 31: $79-90$.

9. Mellanby K. The incidence of scabies In: Scabies. Hampton E.W., Classey, eds 1972; 48-8.

10. Habid Ansarin, MD; Mir Haddi Aziz Jalali, MD; Shadi Mazlooni, MD; Razieh Soltani-Arabshahi, MD; Roya Setarehshenas, MD. Scabies presenting with bullons pemphigoid-like lesions. Dermatol Online J. 03/01/ 2006. 11. Meinking TL, Taplin D, Hermida JL, Pardo R, Kerdel FA. The treatment of scabies with Ivermectin. N England J Med 333:26; 1995.

12. Ismael A. Conti Diaz and Jorge Amaro. Treatment of human scabies with oral ivermectin.. Rev. Inst. Med. Trop. S. Paulo Vol. $41 \mathrm{~N}^{\circ} 4$ Sao Paulo July/August 1999. 13. Heukelbach J, feldmeir H. Ectoparasites - the underestimated realm. Lancet 2004 Mar 13; 363 (9412): 889 -91 .

14. Chouela E, Abeldano A, Pellerano G, Hermandez MI. Diagnosis and treatment of scabies: A practical guide. Am J Clin Dermatol. 2002; 3(1): 9 - 18 


\section{Author Information}

\section{Josephine Mbuagbaw}

Dermatologist, Dermatology sub unit, Department of Medicine, Faculty of Medicine and Biomedical Sciences, University of Yaoundé I

\section{Cecile Bisseck}

Dermatologist, Dermatology sub unit, Department of Medicine, Faculty of Medicine and Biomedical Sciences, University of Yaoundé I

\section{Gladys Ozoh}

Dermatologist, Department of Dermatology, University of Nigeria Teaching Hospital

\section{Mpoudi-Ngole Etienne}

Dermatologist, Dermatology sub unit, Military Hospital 